\title{
Off licence and off label prescribing in children: litigation fears for physicians
}

\section{P Hill}

Arch Dis Child 2005;90(Suppl I):i17-i18. doi: 10.1136/adc.2004.058867

So-called "off label" and unlicensed prescribing refers to the use of medicines outside of the indications for which they are licensed by national regulatory bodies. Off label prescribing is quite common in children, as most drugs are developed only on the basis of trials with adults.

Nevertheless, physicians and hospitals can be wary of using medicines in this way for fear of litigation if adverse events occur. Given this unsatisfactory state of affairs, regulatory bodies are beginning to request robust data from pharmaceutical companies with regard to the use of their products in children. In the meantime, off label prescribing remains acceptable if there is no suitable alternative and physicians are confident that they are using agents in accordance with the body of respected medical opinion.

Correspondence to: Professor P Hill, Department of Psychological Medicine, Great Ormond Street Hospital for Children, Great Ormond Street London WCIN 3JH, UK; prof@17wimpole.com
M istaken ideas about licensing persist in spite of clarifications by, for instance, the Royal College of Paediatrics and Child Health $^{1}$ and the British Paediatric Association. ${ }^{2}$ For instance, consultants frequently voice concerns as to whether the prescription of an unlicensed drug will render them liable to disciplinary or litigious action.

A licence is a marketing authorisation issued by a national regulatory body (Medicines and Healthcare products Regulatory Agency (MHRA) in the UK; European Medicines Agency (EMEA) for the European Union; Food and Drug Administration (FDA) in the USA) enabling a pharmaceutical company to market its product. It is granted following an application by the company which must be supported by data on safety and efficacy relevant to a particular clinical indication and a particular age group. The application is paid for by the company, directly through a fee, and indirectly through the cost of clinical trials that are required to yield safety and efficacy data. The decision to apply for a licence will therefore be influenced by commercial considerations of whether the cost of obtaining a licence will be recoverable by volume of sales.

The use of licensed medicines outside the condition of the licence is referred to as "off label", an expression that derives from a term used in the US authorisation process: FDA approved product labelling. Some medicines given to children, such as melatonin, have never been considered for a licence and are thus unlicensed.
OFF LABEL PRESCRIBING FOR CHILDREN

Various studies have shown that prescribing unlicensed or off label medication is more frequent for children than for adults. ${ }^{3}$ Many medicines prescribed for children and adolescents are either not licensed for under 18 year olds (for example, amiloride), the route of administration is not the one for which it has been approved (for example, oral midazolam), or the product is not licensed at all (for example, caffeine). In addition, there are also compounds that are licensed for children, but not for adults (for example, methylphenidate).

The prescription of off label and unlicensed medicines for children applies especially in neonatal medicine and hospital practice, ${ }^{4-8}$ but it is also quite prevalent in the community, where the much larger numbers of children mean that it is a major issue. ${ }^{9-12}$ Data from selected studies are shown in table 1.

\section{THE SITUATION IN THE UK}

Doctors are allowed to prescribe off label. In the UK, this is covered by the Medicines Act 1968 and the EC Pharmaceutical Directive 89/341/EEC which outlines requirements of the EEC pharmaceutical legislation relating to medicinal products for human use. ${ }^{13}$ However, the recent usage by the MHRA of terms such as "contraindicated" in its statement about the use of drugs (for example, selective serotonin reuptake inhibitors (SSRIs)) in children seems to intrude into medical practice rather than pharmaceutical marketing regulation. ${ }^{14}$ Managing authorities, such as NHS Trusts or individual practices, on the other hand, may issue guidelines discouraging or even prohibiting the use of off label or unlicensed medications. Individual doctors may fear litigation by parents if there are adverse reactions to such medicines. Indeed, adverse reactions are more common than with licensed drugs, partly because dosing schedules for drugs developed with reference to adult populations have often not been assessed for children. ${ }^{15}$ In some countries reimbursement of off label or unlicensed prescriptions costs by medical insurance may be refused. ${ }^{4}$

\section{FUTURE TRENDS}

The current situation regarding the licensing of medicines for children is a profoundly unsatisfactory state of affairs both for children and their doctors. In the US, the FDA has taken several steps to improve matters, including an initiative which requires pharmaceutical companies to

Abbreviations: EMEA, European Medicines Agency; FDA, Food and Drug Administration; MHRA, Medicines and Healthcare products Regulatory Agency. 
Table 1 European examples of unlicensed and off label prescribing for children

\begin{tabular}{|c|c|c|c|c|}
\hline Reference & $\begin{array}{l}\text { Prescribing } \\
\text { site }\end{array}$ & $\begin{array}{l}\text { Unlicensed } \\
(\%)\end{array}$ & $\begin{array}{l}\text { Off label } \\
(\%)\end{array}$ & $\begin{array}{l}\text { Unlicensed and } \\
\text { off label }(\%)\end{array}$ \\
\hline$t^{\prime}$ Jong et $a l^{7}$ & $\mathrm{ICUs}$ & 54.0 & 17.8 & 71.8 \\
\hline Conroy et $a l^{5}$ & Wards & 7.0 & 39.0 & 46.0 \\
\hline $\begin{array}{l}\text { Chalumeau } \\
\text { et al }\end{array}$ & Outpatients & 4.0 & 29.0 & 33.0 \\
\hline Mclntyre et $a l^{10}$ & $\begin{array}{l}\text { General } \\
\text { practice }\end{array}$ & 0.3 & 10.5 & 10.8 \\
\hline
\end{tabular}

ICUs, intensive care units.

review their data to see if adult derived data on effectiveness or dosing can be extrapolated to children. In a paper reviewing this issue it was pointed out that there are occasions where the reverse may apply-approval for a drug indication in childhood may need to be extended into adulthood. ${ }^{16}$ Attention deficit/hyperactivity disorder (ADHD) is a clear instance of this. It is becoming increasingly recognised that as new products come to market, regulatory agencies internationally are requiring pharmaceutical companies to obtain rigorous and comprehensive paediatric data as part of their submission, and rightly so.

For the present, it is accepted that off label and off licence prescribing in paediatric practice is acceptable and necessary when no suitable alternative to the required treatment is available. ${ }^{17}$ Although ultimate legal responsibility lies with the prescriber, the prescription of these treatments does not constitute a breach of duty as long as the prescriber can rely on information and guidance from a respected body of medical opinion. ${ }^{17}$ In the UK, the publication Medicines for Children, ${ }^{1}$ produced by the Royal College of Paediatrics and Child Health, is generally cited as representing the respected body of knowledge, because broad consensus among a large number of UK paediatricians was obtained as to its content and recommendations.

\section{REFERENCES}

1 Royal College of Paediatrics and Child Health. Medicines for children, 2nd edition, 2003.

2 British Paediatric Association \& Association of the British Pharmaceutical Industry. Licensing medicines for children. London: Royal College of Paediatrics and Child Health, 1996.

3 Collier J. Paediatric prescribing: using unlicensed drugs and medicines outside their licensed indications. Br J Clin Pharmacol 1999;48:5-8.

4 Bücheler R, Schwab M, Mörike K, et al. Off label prescribing to children in primary care in Germany: retrospective cohort study. BMJ 2002;324:1311-12.

5 Conroy S, Choonara I, Impicciatore P, et al. Survey of unlicensed and off label drug use in paediatric wards in European countries. BMJ 2000;320:79-82.

6 't Jong GW, Vulto AG, de Hoog M, et al. Unapproved and off label use of drugs in a children's hospital. N Engl J Med 2000;343:1125.

7 't Jong GW, Vulto AG, de Hoog M, et al. Survey of the use of off-label and unlicensed drugs in a Dutch children's hospital. Pediatrics 2001;108:1089-93

8 Turner S, Longworth A, Nunn AJ, et al. Unlicensed and off-label drug use in paediatric wards: prospective study. BMJ 1998;318:343-5.

9 Chalumeau M, Tréluyer JM, Salanave B, et al. Off-label and unlicensed drug used among French office based paediatricians. Arch Dis Child 2000;83:502-5.

10 Mclntyre J, Conroy S, Avery A, et al. Unlicensed and off-label prescribing of drugs in general practice. Arch Dis Child 2000;83:498-501.

11 Schirm E, Tobi H, deJong-van den Berg LTW. Unlicensed and off label drug use by children in the community: cross sectional study. BMJ 2002;324:1312-13.

12 't Jong GW, Eland IA, Sturkenboom MCJM, et al. Unlicensed and off label prescription of drugs to children: population based cohort study. BMJ 2002:324:1313-14.

13 Council Directive 89/341/EEC of 3 May 1989. Available at http:// europa.eu.int (accessed 14 November 2004).

14 Medicines, Healthcare products Regulatory Agency (MHRA). Available at http://www.mhra.gov.uk/ (accessed 14 November 2004).

15 Turner S, Nunn AJ, Fielding K, et al. Adverse drug reactions to unlicensed and off label drugs on paediatric wards: a prospective study. Acta Paediatrica 1999;88:965-8.

16 Laughren TP. Regulatory issues in paediatric pharmacology. J Am Acad Child Adolesc Psychiatry 1996;35:1276-82.

17 Evans H, Rylance G. Paediatric prescribing in the non-specialist setting. Prescribers' Journal 2000;40:138-44. 